\title{
Fabrication of Ion-Induced Carbon Nanocomposite Fibres and their Application to Magnetic Force Microscope Probes
}

\author{
Masaki Tanemura ${ }^{1}$ and Masashi Kitazawa ${ }^{2}$ \\ ${ }^{1}$ Nagoya Institute of Technology, \\ 2Olympus Co. Ltd., \\ etpan
}

\section{Introduction}

1-dimensional (1-D) nanocarbon materials, such as carbon nanotubes (CNTs) (Iijima, 1991) and carbon nanofibres (CNFs; 1-D nanocarbon without a hollow structure), are quite "hot" in the materials science field, and a variety of applications is now being tackled, such as scanning probe microscope (SPM) tips, field electron emission devices, nanoelectronics devices, capacitors, catalysts supports, hydrogen storage, and so on. For their synthesis, arc discharge (Iijima, 1991), laser ablation (Thess et al., 1996), and chemical vapor deposition (CVD) (Pan et al., 1998; Ren et al., 1998; Tanemura et al., 2001) have conventionally been employed. In those methods, however, growth temperatures higher than $500^{\circ} \mathrm{C}$ are generally required. From a standpoint of an eco-process and for their applications to flexible devices using plastic substrates, however, they should be grown at lower temperatures, ideally at room temperature (RT). In this respect, plasma-enhanced CVD at and below about $120^{\circ} \mathrm{C}$ has been attempted (Boskovic et al., 2002; Hofmann et al., 2003). In this chapter, we will deal with a new approach to synthesize carbon nanocomposite fibres at room temperature and their applications to scanning force microscope probes.

\section{Room-temperature fabrication of ion-induced carbon-based nanofibres}

Ion-irradiation to solid surfaces sometimes induces the formation of nano- to micro-sized surface structures, such as ripples, pyramids, conical protrusions and whiskers, even at RT (Auciello \& Kelly, 1984; Czanderna et al., 1998). In addition, surface texturing is sometimes enhanced by a simultaneous supply of so-called "seed" materials which are different from the constituent of the target surface during ion irradiation (Wehner, 1985; Tanemura et al., 2004). These imply that ion irradiation must be promising as a basic technique to fabricate nanomaterials or nanostructures at low temperatures. In what follows, based on this strategy, carbon-based nanofibres (pristine and carbon nanocomposite fibres) are fabricated using the ion irradiation method.

\subsection{Pristine carbon nanofibres}

In 1980s, before the discovery of CNTs, one of the main topics in the materials science was the growth of whiskers which were generally larger in size than CNFs. For the whisker 
growth, an ion irradiation onto graphite surfaces was attempted by several groups using normal-incident ion-beams, and following features had been revealed (Floro et al., 1983; Vechten et al., 1987). (1) Whiskers exhibit an initial rapid growth process of "leads" or "fine whiskers" followed by a slower diffusion-fed process (to form whiskers). (2) All of the fine whiskers point in the incidence direction of the ion beam. (3) Whiskers never grow on diamond or glassy carbon surfaces. Because those investigations focused mainly on the whisker growth, the fine whiskers, which corresponds to the present CNFs, have been treated merely as a precursor to ion-induced C-whiskers and paid little attention. For this reason, features of ion-induced $\mathrm{CNF}$ s have yet to be fully revealed.

Figure 1(a) shows a typical scanning electron microscope (SEM; JEOL JEM-5600) image of an ion-induced CNF on a glassy carbon surface irradiated with $\mathrm{Ar}^{+}$ions of $3 \mathrm{keV}$ at $55^{\circ}$ from the normal to the substrate with a simultaneous supply of Mo at RT (Tanemura et al., 2004b). As seen in Fig. 1(a), a conical protrusion is formed on the surface, and a linearshaped single $\mathrm{CNF}, \sim 50 \mathrm{~nm}$ in diameter and $\sim 1 \mu \mathrm{m}$ in length, grow on the tip. Both the basal cone and the CNF are pointing in the ion-beam direction. In the ion-irradiation method, CNFs generally grow only on the cone tips, and more than one CNF never grow on the respective cone tips [Fig. 1(a)]. One of the key factors to induce the ion-induced CNF growth is the ion incidence angle (Tanemura et al., 2005a; Yusop et al., 2010). The ion irradiation at normal incidence is not an optimum condition for the CNF growth, and this may be a reason why the whiskers did not grow on the diamond and glassy carbon surfaces in the previous work done using normally incident ions.
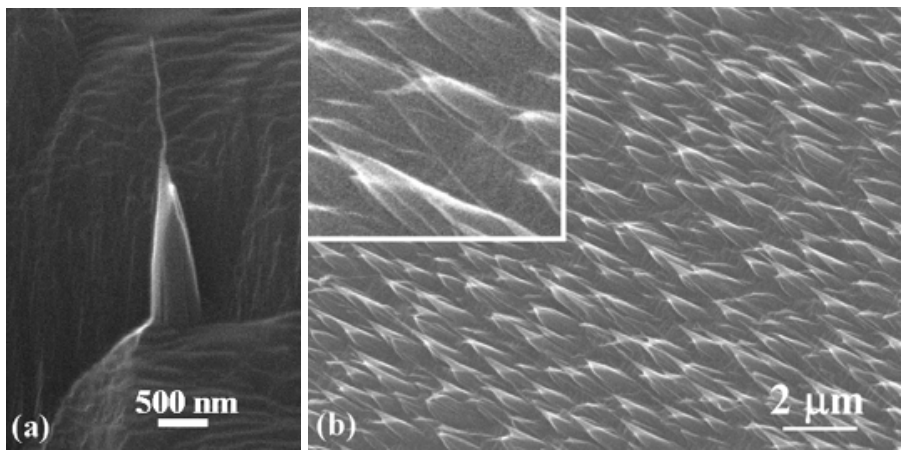

Fig. 1. SEM images of (a) isolated and (b) densely distributed CNFs formed on glassy carbon and carbon-coated $\mathrm{Si}$ surfaces irradiated with $\mathrm{Ar}^{+}$ions at $55^{\circ}$ from the normal to the surface at RT. Inset in (b): Enlarged image. (Tanemura et al., 2004b; Tanemura et al., 2006a.)

For oblique ion irradiation, densely distributed CNFs are fabricated on not only bulk carbon but also carbon coated substrates without any simultaneous metal supply at RT (Tanemura et al., 2005b; Tanemura et al., 2005c). Figure 1(b) shows a typical example of those formed on a carbon-coated Si surface, revealing that ion-irradiated surface is covered with densely distributed CNF-tipped cones. (Tanemura et al., 2006a). The ion-induced CNFs, which were formed on almost all of the cones [inset of Fig. 1(b)], were linear-shaped and aligned in the ion-beam direction. They were $0.3-1 \mu \mathrm{m}$ in length, and almost uniform in diameter, $\sim 20 \mathrm{~nm}$, in the growth direction independent of the CNF length. CNF size was independent of the cone size. It should be also mentioned the ion-irradiation method requires no heat supply. This allows us a greater choice of substrates. In fact, densely distributed CNF-tipped cones 
grow also on carbon coated plastic substrates (Tanemura et al., 2006a; Tan et al., 2006; Sim et al., 2007). Another feature of ion-induced CNFs is that the higher ion-incidence angle (ion irradiation at oblique direction) produces CNFs of smaller diameter (Tanemura et al., 2005a; Yusop et al., 2010).

The formation of ion-induced CNFs are also possible by $\mathrm{Ne}^{+}$and $\mathrm{Xe}^{+}$ions as well as by $\mathrm{Ar}^{+}$ ions (Yamaguchi et al., 2008). Figure 2 shows a comparison of CNFs grown on graphite surfaces by $\mathrm{Ne}^{+}, \mathrm{Ar}^{+}$and $\mathrm{Xe}^{+}$ions of $1000 \mathrm{eV}$ at $45^{\circ}$ from the normal to the surface. The formation of ion-induced CNFs was prominent for the irradiation with lighter mass ions. Longer and denser CNFs tended to grow by lighter-mass-ion irradiation, and finer CNFs were formed by heavier-mass-ion irradiation. In an ion-energy range of 450-1000 V, the higher the ion energy, the longer the length of the ion-induced CNFs. It should be mentioned that the surfaces sputtered by $\mathrm{Xe}^{+}$ions at and less than $600 \mathrm{eV}$ were characterized by sparsely distributed cones and any CNF was not formed thereon. Thus, the size and numerical density are controllable by the ion-irradiation parameters.

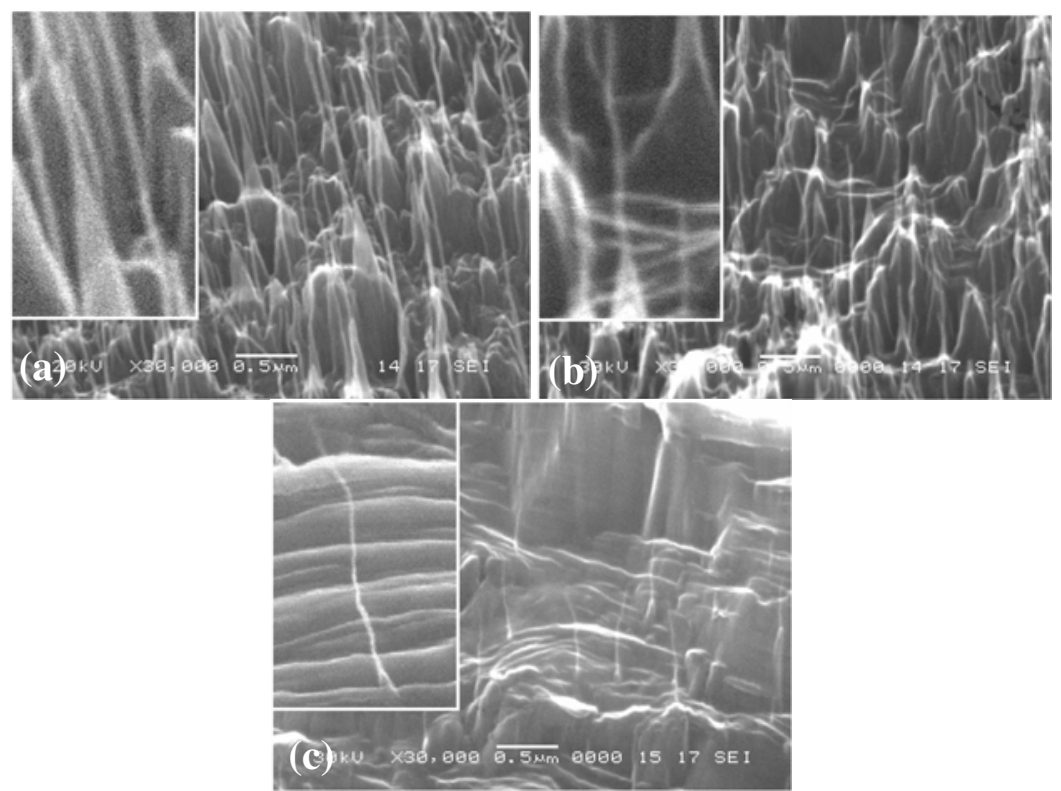

Fig. 2. Graphite surfaces sputtered with (a) $\mathrm{Ne}^{+}$, (b) $\mathrm{Ar}^{+}$and (c) $\mathrm{Xe}^{+}$of $1 \mathrm{keV}$. Insets: Enlarged SEM images. (Yamaguchi et al., 2008).

Figure 3(a) shows a typical transmission electron microscope (TEM; JEOL JEM-3010) image of a CNF-tipped cone formed on an edge of a graphite foil irradiated by $\mathrm{Ar}^{+}$ions (Takeuchi et al., 2008a). For the TEM observation, the ion-irradiated graphite foil was directly mounted on a TEM sample holder without any post-treatment. The CNF was $\sim 20 \mathrm{~nm}$ in diameter and longer than $500 \mathrm{~nm}$ in length. No clear boundary between the CNF and the conical tip was recognizable. In addition, no hollow structure was observed in CNFs, suggesting that they were not CNTs but CNFs. Figures 3(b) and 3(c) show the electron diffraction patterns (EDPs) taken at a middle part of the CNF and a stem regions of the cone, respectively. The EDP from the stem region of the cone featured the spotty rings arising 
from the graphite lattice [Fig. 3(c)], disclosing that the stem part of the cones maintained the polycrystalline nature of the graphite substrate. An EDP taken at around a cone tip region consisted of diffraction spots associated with graphite and hallow-like rings, and number of the graphite associated spots was reduced compared with the EDP from the stem region, implying that the graphite nature was less prominent at the cone tip. By contrast, only hallow-like rings were observed in the EDP from the CNF, suggesting the amorphous-like or very fine-crystallite structure of the CNF [Fig. 3(b)]. The observed crystallographic features were similar to those observed for CNFs grown on a carbon-coated Ni mesh (Tanemura et al., 2005b). Hofmann et al. also reported that CNTs synthesized by plasmaenhanced CVD at $120^{\circ} \mathrm{C}$ were low in graphitization quality (Hofmann et al., 2003). Thus, the amorphous-like nature is a feature common to carbon nanomaterials grown at low temperatures.

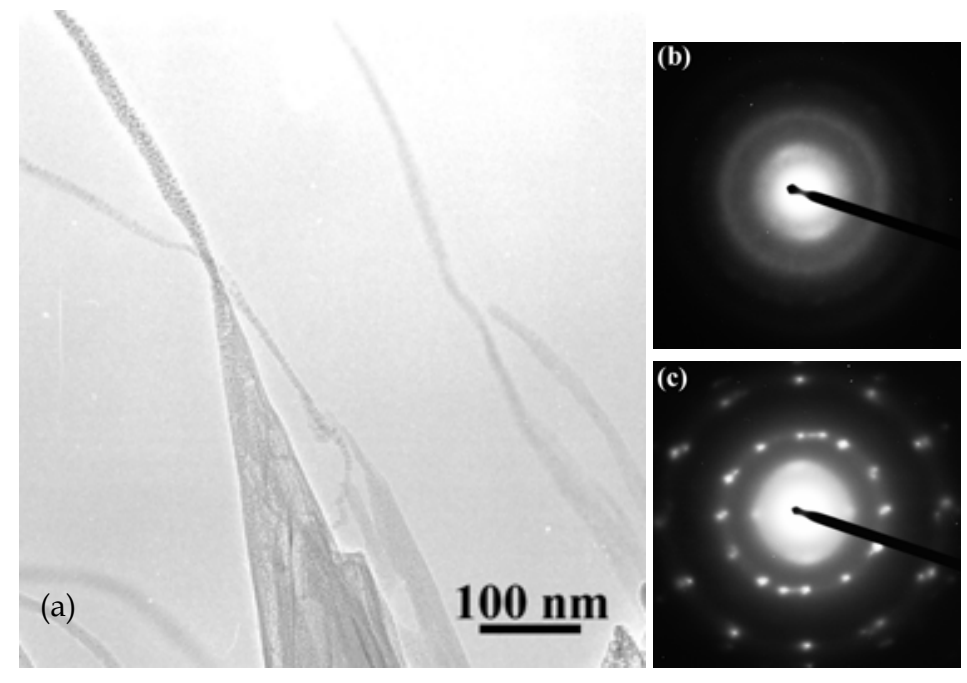

Fig. 3. Typical TEM image of a pristine CNF formed on a graphite foil. (b) and (c) EDPs from a middle part of the CNF and a stem region of the cone in (a), respectively. (Takeuchi et al., 2008a)

The growth mechanism of ion-induced CNFs is thought to be as follows (Tanemura et al., 2004b; Tanemura et al., 2005b; Tanemura et al., 2005c; Tanemura et al., 2006b): (i) Formation of conical protrusions, (ii) re-deposition of carbon atoms sputter-ejected from the sample surface onto the sidewall of the conical protrusions, and (iii) the surface diffusion of the redeposited carbon atoms toward the tips during sputtering (Fig. 4). Because the ion irradiations at elevated temperatures, such as $300^{\circ} \mathrm{C}$, were favourable for the longer CNF growth on graphite substrates compared with RT fabrication, it is obvious that the surface diffusion plays a decisive role in the growth of ion-induced CNFs (Yusop et al., 2010).

\subsection{Carbon nanocomposite fibres}

From a viewpoint of applications, carbon-based nanocomposites are fascinating compared with pristine nanocarbon, due to the wider potential application fields, such as an ultra-high density memory media. Thus, the synthesis of CNTs encapsulating ferromagnetic metals 


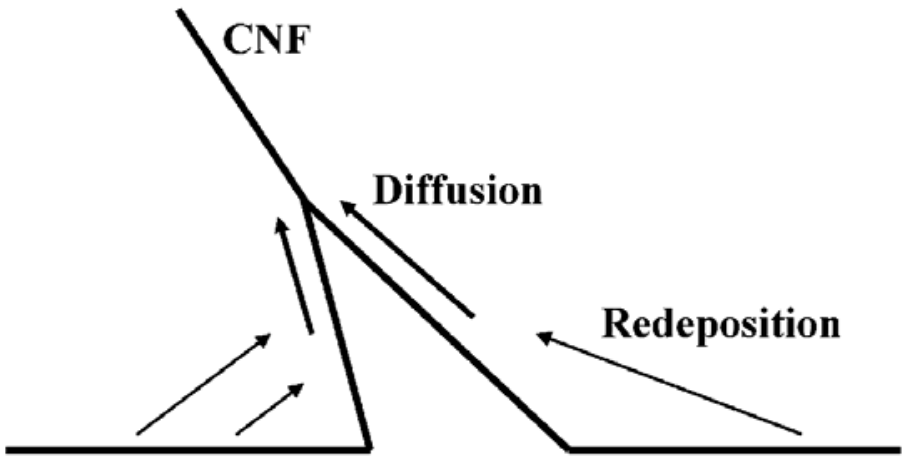

Fig. 4. Growth mechanism of ion induced CNFs.

has been attempted by CVD methods (Bao et al., 2002; Leonhardt et al., 2003; Alexandrou et al., 2004; Schneider et al., 2004; Tyagi et al., 2005; Elías et al., 2005). For their synthesis, however, besides the high growth temperatures required, the metals which could be encapsulated in CNTs are mainly limited to the catalyst used for the CNT growth. By contrast, in the ion irradiation method in principle, various kinds of metals can be incorporated into ion-induced CNFs by a simultaneous supply of metals during $\mathrm{Ar}^{+}$-ion irradiation to carbon or carbon coated substrates at low temperatures.

Figure 5 shows SEM images of graphite surfaces sputtered with a simultaneous Ni supply at a supply rate (D) of 6.0, 7.8 and $15 \mathrm{~nm} / \mathrm{min}$ (Takeuchi et al., 2008a). The surface sputtered with a small Ni supply $(\mathrm{D}=6.0 \mathrm{~nm} / \mathrm{min}$ ) was characterized by CNF-tipped cones similar to the graphite surfaces ion-irradiated without Ni supply [Fig 5(a)]. Ni-supplied CNFs, $20-50$ $\mathrm{nm}$ in diameter and $0.3-5 \mu \mathrm{m}$ in length, were similar to the pristine CNFs in size, whereas in their shape they showed a tendency to curve [see inset in Fig 5(a)]. Such a curved structure was more prominent on the surface sputtered with a moderate Ni-supply [D $=7.8$ $\mathrm{nm} / \mathrm{min}$; Fig 5(b)], which was covered with slender needle-like protrusions and cones. The $\mathrm{Ni}$-supplied CNFs grown thereon were not so well aligned, and many of them were curved or waved. They were $30-50 \mathrm{~nm}$ in diameter and $0.5-5 \mu \mathrm{m}$ in length, and some of them were not uniform in diameter in the growth direction. Thus, the morphology of CNFs was much influenced by $\mathrm{Ni}$ supply. As seen below, this may be due to the difference in crystalline structure between Ni-supplied and pristine CNFs.

Another important feature seen in Fig. 5(b) is that the needle-like protrusions or cones do not always possess the CNFs on top. The higher the supply rate, the more manifest this feature, as typically revealed for the surface sputtered with a large Ni supply [D = $15 \mathrm{~nm} / \mathrm{min}$; Fig 5(c)]. No CNF was formed on the tops, though the surface featured various sizes of conical structures. Thus, the CNF growth was suppressed by the excess Ni supply. As described above, CNFs are thought to grow due to the redeposition of sputter-ejected carbon atoms onto the sidewall of conical protrusions and the excess surface diffusion of the carbon atoms to the tips during $\mathrm{Ar}^{+}$ion irradiation (Tanemura et al., 2004b; Tanemura et al., 2005b; Tanemura et al., 2005c; Tanemura et al., 2006b). Excess Ni atoms simultaneously supplied would reduce the surface diffusion of carbon atoms to suppress the formation of CNFs.

Figure 6 shows a typical TEM image of a Ni-supplied CNF formed on a cone (Takeuchi et al., 2008a). Similar to the pristine CNFs (Tanemura et al., 2005a; Tanemura et al., 2005b), no boundary between the CNF and the cone was recognizable. In addition, no hollow 

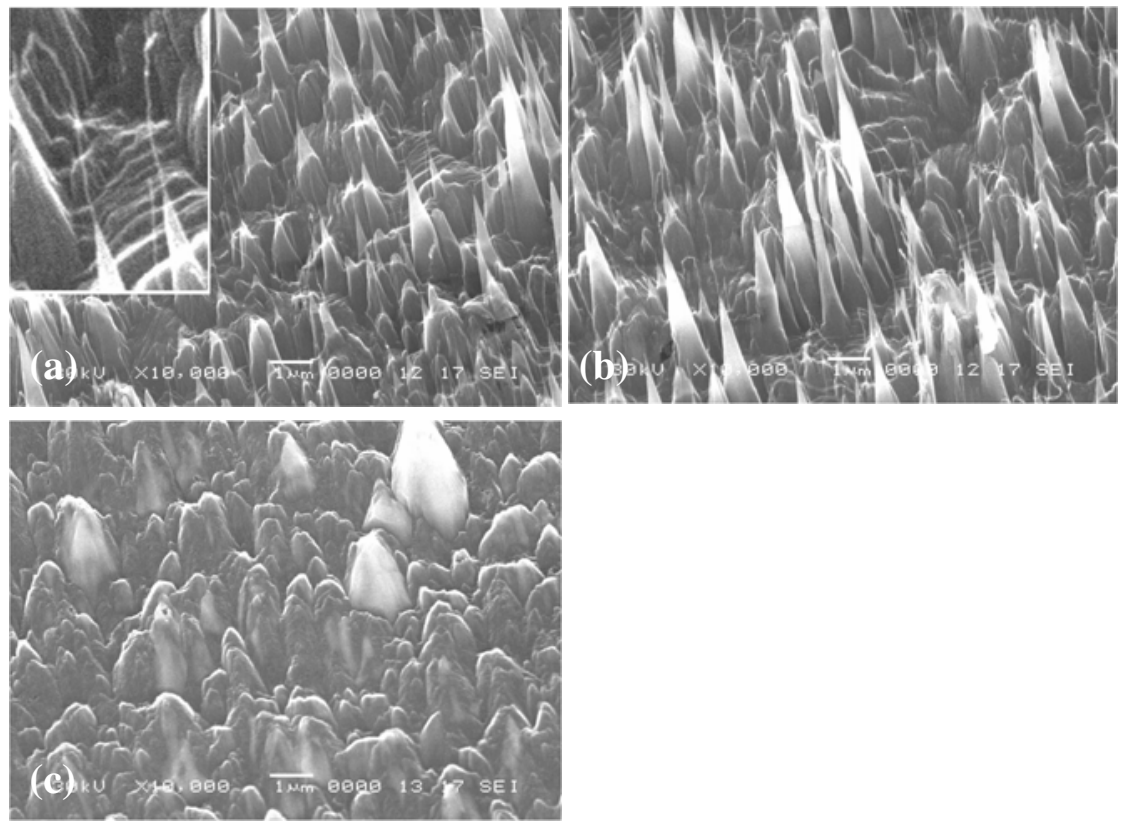

Fig. 5. SEM images of graphite surfaces sputtered with a simultaneous Ni supply at $\mathrm{D}=(\mathrm{a})$ 6.0, (b) 7.8 and (c) $15 \mathrm{~nm} / \mathrm{min}$. Insets in (a): Enlarged SEM image. (Takeuchi et al., 2008a)
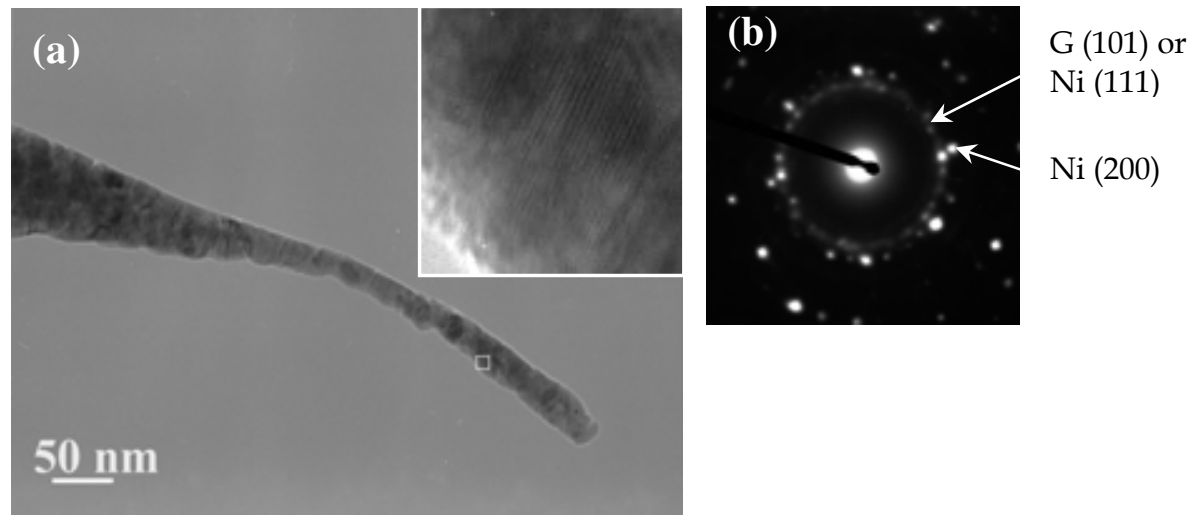

Fig. 6. (a) Typical TEM image of a Ni-supplied CNF grown on a cone. (b) EDP from the tip region of the Ni- supplied CNF. Inset in (a): enlarged image of the rectangular area in (a). (Takeuchi et al., 2008a)

structure was observed, implying that it is not tubular, but fibrous unfortunately. Figure 6(b) shows an EDP taken at the tip region of the CNF. The EDP consisted of spotty rings arising from $\mathrm{Ni}$ (111) or graphite (101) (the 1st inner ring) and $\mathrm{Ni}$ (200) (the 2nd inner ring). Thus, the CNF was characterized by the polycrystalline nature, and Ni was surely included in the CNF, namely the Ni-C nanocomposite fibre (Ni-CNF). From a careful TEM analysis 
of the Ni-CNF, fine moire fringes were observed in several regions of the Ni-CNF [inset in Fig. 6(a)]. This suggests a stack of crystallites in the radial direction of the Ni-CNF. In other words, the Ni-CNF is not simply composed of the Ni grains linearly coalesced in Ni-CNF growth direction whose dimension is comparable to the diameter of the Ni-CNF.

Similar morphological and crystallographic features are observed also for $\mathrm{Co}$ and $\mathrm{Fe}$ supplied CNFs (Wang et al., 2009; Wang et al., 2010a-c). In every case, with increasing the supply rate, the CNFs are suppressed in formation and tend to be curved. The metalsupplied CNFs possess no clear hollow structure, implying that they are not tubular but fibrous. Although Ni, Fe and Co are known to be typical catalysts for the CNT growth in CVD method, coexistence of those metals and $C$ do not induce the formation of tubular structure in the ion-irradiation at room temperature. The process temperature may be too low to form the tubular structure, namely, CNTs. It should be also noted that with decreasing the metal supply rate, both metal content and the crystallinity of incorporated metals in CNFs decrease. As seen in Fig. 7, for example, CNFs formed with Fe supply at lower supply rates were characterized by broader Debye rings in EDP, suggesting that the nanofibres were amorphous-like or fine crystalline in structure (Wang et al., 2010a).

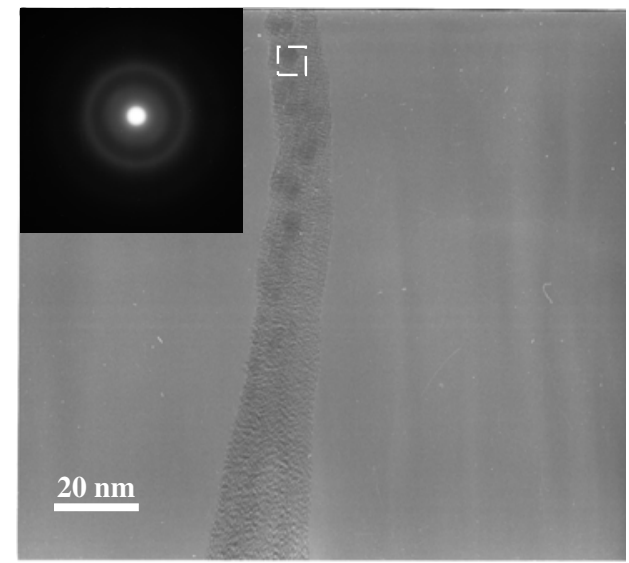

Fig. 7. Typical TEM image and EDP (inset) of an Fe supplied CNF grown on a graphite foiles at $\mathrm{D}=2.0 \mathrm{~nm} / \mathrm{min}$. (Wang et al., 2010a)

Metal-carbon nanocomposite fibres can be fabricated also on metal substrates by a simultaneous supply of carbon during ion irradiation without pre-coating of a carbon film. Figure 8 shows SEM images of CNFs directly grown on $\mathrm{Cu}$ meshes (Zamri et al., 2010). For the carbon supply, the $\mathrm{Cu}$ meshes were placed on a graphite plate and both the $\mathrm{Cu}$ meshes and the graphite plate were co-sputtered with $\mathrm{Ar}^{+}$ions. The carbon plate acted as the $\mathrm{C}$ supply for CNFs growth on metal mesh substrates. The sputtered carbon, unfortunately, was not supplied uniformly over the whole sample surface. So, the CNFs were observed only at a limited area on $\mathrm{Cu}$ mesh substrates. Similar to the CNFs grown on carbon substrates, only single CNFs grew on the respective cones and no CNF grew without cone bases. The SEM images clearly indicated that the morphology of the CNFs thus grown were highly depends upon sputtering time. On the $\mathrm{Cu}$ mesh sputtered for 30 minutes nanoneedles with fibre length of $<1 \mu \mathrm{m}$ were formed [Fig. 8(a)], while CNFs grown after the irradiation for 45 minutes were $\sim 2.5 \mu \mathrm{m}$ in average length [Fig. 8(b)]. By contrast, the $\mathrm{Cu}$ 
mesh sputtered for 60 min revealed large needles and the density of the CNFs thereon was quite low. The average length of the CNFs was $<1.5 \mu \mathrm{m}$. On Mo meshes also, CNFs were observed to form directly (Zamri et al., 2010).

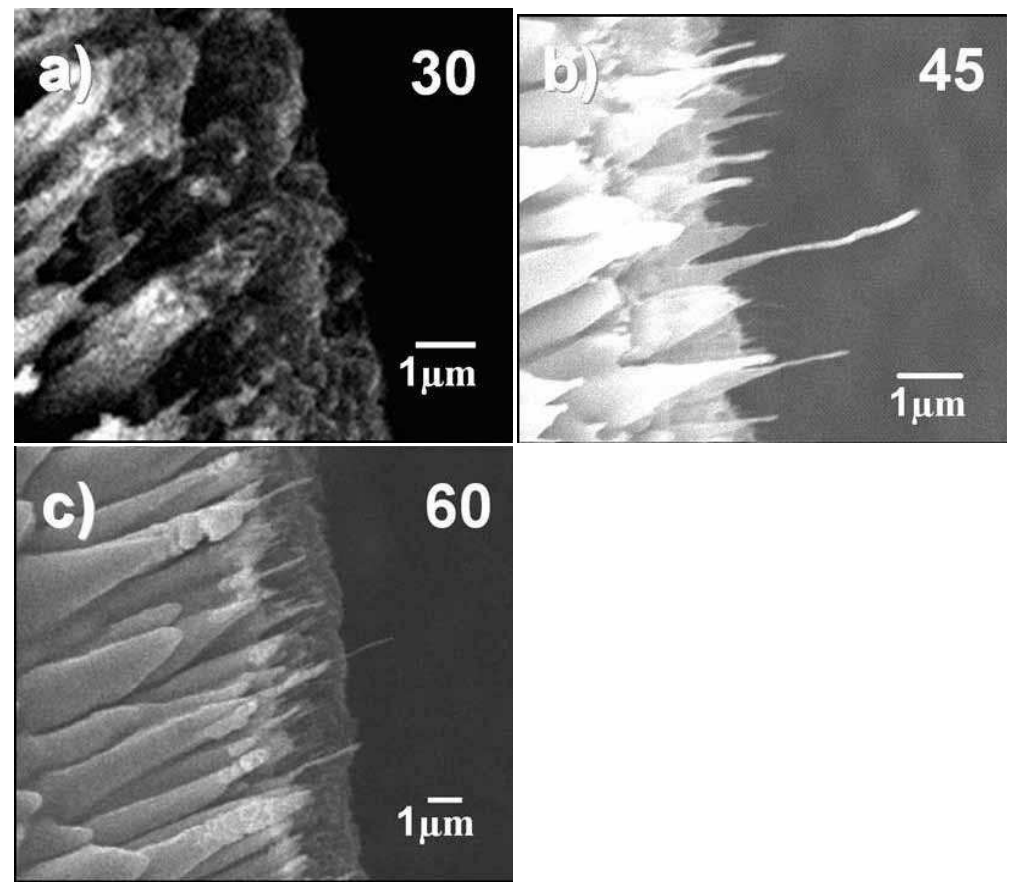

Fig. 8. SEM images of the morphology of $\mathrm{Cu}$ meshes after $\mathrm{Ar}^{+}$ion bombardment with a simultaneous C supply for (a) 30, (b) 45 and (c) $60 \mathrm{~min}$. (Zamri et al., 2010)

Figure 9(a) shows a typical TEM image of an as-received CNF contacting with a W nanoprobe of counter electrode (Zamri et al., 2010) to measure the electric property of the $\mathrm{CNF}$. The CNF was formed on a Cu mesh by sputtering for $45 \mathrm{~min}$. As shown in the high magnification image [Fig. 9(b)], dark contrast regions dispersed in the whole area of the CNF. So the CNFs formed directly on the $\mathrm{Cu}$ mesh seem to be composite nanofibres. Figure 9(c) represents a selected area EDP at the centre of the fibre. The EDP revealed that the CNF is amorphous-like or fine crystalline in nature. In the EDP, however, the Debye ring was too broad to identify the element contained in the fibre. As seen later, the dark and bright contrast regions in Fig. 9(b) might correspond to $\mathrm{Cu}$ and $\mathrm{C}$ phases, respectively.

For metal-composite CNFs, a control in crystalline structure was to some extent possible by the electron current flow through the fibres. To investigate the structural transformation of this $\mathrm{Cu}$ composite $\mathrm{CNF}$ by the electron current flow, a low voltage up to $1 \mathrm{mV}$ at an incremental step of $0.2 \mathrm{mV}$ was applied to it with a $4.5 \mathrm{k} \Omega$ resistor connected in series while observing its crystalline structure at about $\times 100,000$ (Zamri et al., 2010). The experimental time for this current-voltage (I-V) measurement was $130 \mathrm{sec}$. Just after the I-V measurement was started, a sudden dramatic change in TEM contrast was observed in the composite CNF and no further dramatic change was recognized during the I-V measurement. Figure 10(a) shows a TEM image taken after the I-V measurement. It should be stressed that after the I-V 


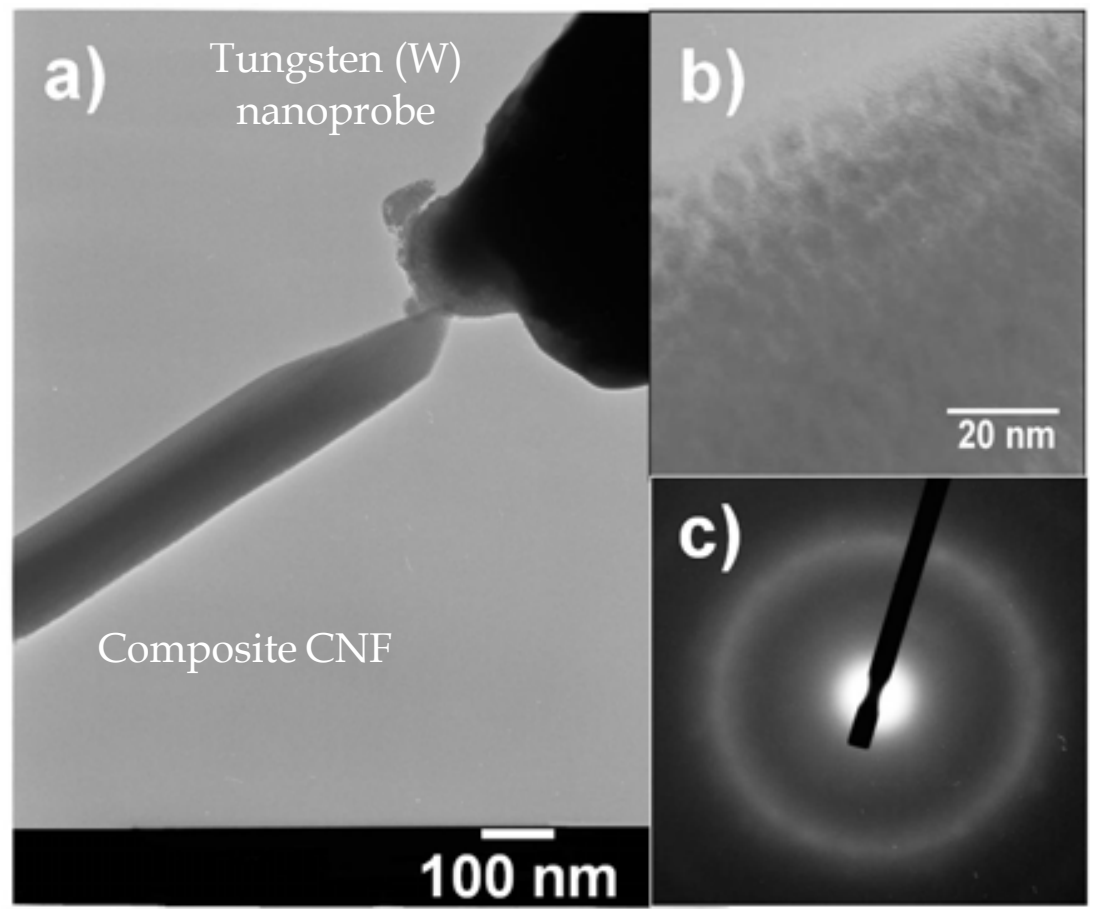

Fig. 9. TEM images of an as-received CNF formed on a $\mathrm{Cu}$ mesh. (a) A bright field image of a CNFs touching to a W nanoprobe, (b) magnified image of the CNF, and (c) the corresponding EDP. (Zamri et al., 2010)

measurement, the morphology of the composite CNF was changed from linear to wavy, and the crystallinity of the composite CNF was also dramatically reconstructed to a nanocarbon encapsulating a nanowire of polycrystalline nature. In addition, the amorphous carbon transformed to graphene layers at the fibre surface [Figure 10(b)]. Small particles were assembling in the middle of the bundles of graphene layers. It should be also noted that the outer layer of the fibre at which the particles were dispersed, the outer layer composed of bundles of very thin graphene layers (<10 layers) as shown in Figure 10(c). On the other hand, as shown in Figure 10(d), the outer layer parts without particle dispersion possessed very thick (> 80 layers) graphene layers. During the voltage being applied the resistive heating might occur in the composite $\mathrm{CNF}$ and hence inducing the transformation of morphological structure and crystallinity of the composite CNF. Unfortunately, it was impossible to measure the actual temperature increase induced by the current flow. However, the current density reached $265 \mathrm{~A} / \mathrm{cm}^{2}$ even at the current of $30 \mathrm{nA}$. Taking account of its quite tiny volume, the temperature would increase over the recrystallization temperature of the composite CNF to induce the transformation. The structural change induced by an electron current flow was also observed by TEM for a Pt-CNT system (welding of a CNT to Pt surface) (Asaka et al., 2008) 

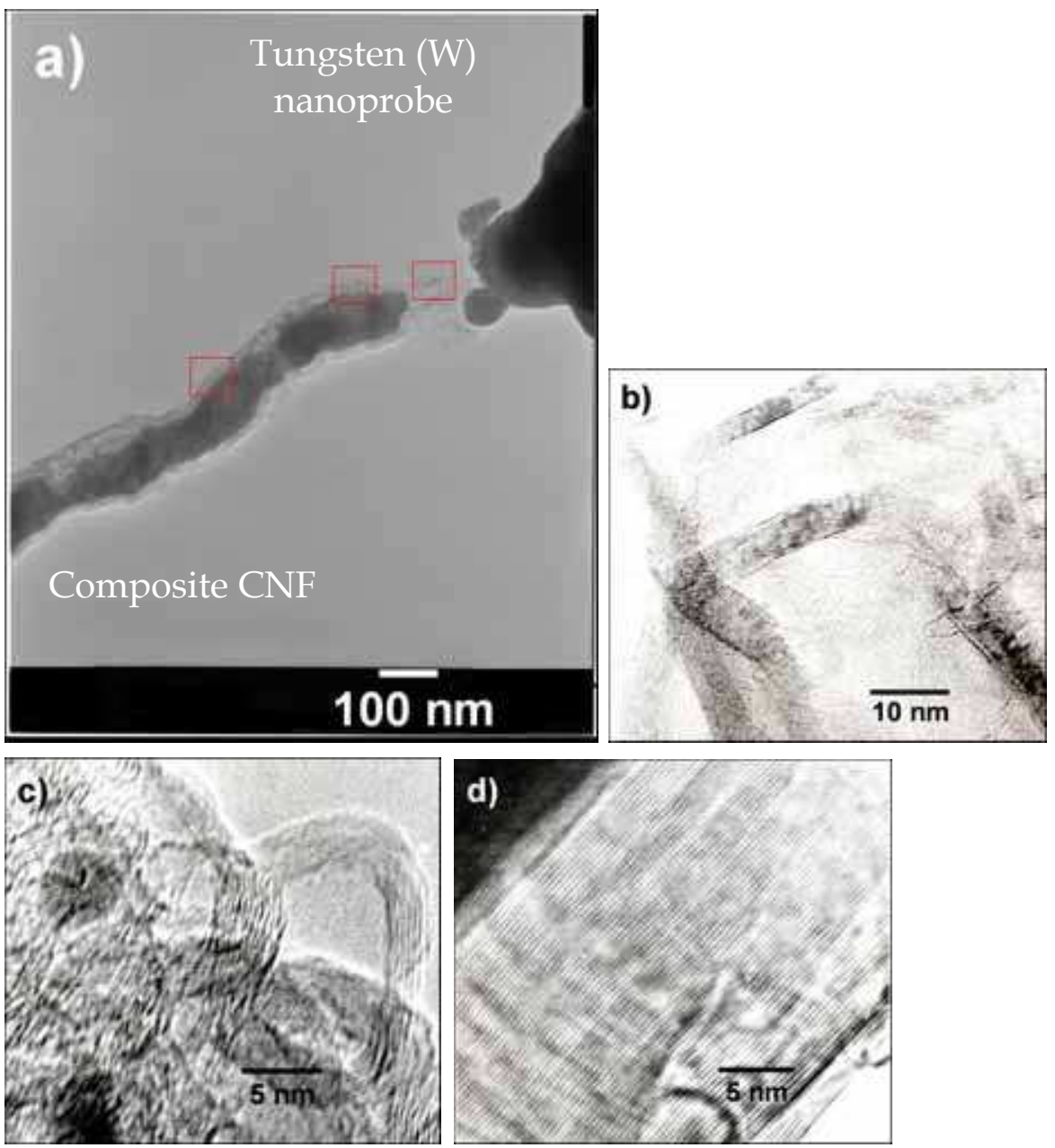

Fig. 10. TEM images of the CNF shown in Fig. 9 taken after the I-V measurement. (a) A bright field image, (b) lattice image of outer layer of the CNF (bundles of graphene layers), (c) lattice image of dispersed particles in the bundles of graphene layers and (d) lattice image of thick graphene layers formed in the outer layer of the CNF. (Zamri et al., 2010)

\section{Nanoprobe application}

Ion-induced carbon-based nanofibres cover many of the application fields of CNTs. Among them, their application to SPM probes will be the most promising in the nearest future. In SPM, localized interaction between a SPM tip and a sample surface is measured as a function of the tip (or sample) position to create an image with an atomic resolution. Thus, essential factors for probes affecting the SPM performance are geometrical factors, namely, sharpness in tip radius and aspect ratio. Sophisticated control in specific property, such as chirality of CNTs, is not required for the probe application. In addition, probes perform well 
independent of a hollow structure of the 1-D nanocarbons. Thus, both CNTs and CNFs are potential candidates for this application. In this chapter, we will deal with the application of the 1-D nanocarbon materials to SPM probes.

\subsection{Batch-fabrication of carbon nanofibre probes}

Since the development of the scanning tunneling microscope (STM) (Binnig et at., 1982), a variety of probe-based microscopes, such as atomic force microscopes (AFMs) and magnetic force microscope (MFM), has been proposed and widely used in the various fields of semiconductor engineering, surface science, biology and so on. Sharpened metal probes and $\mathrm{Si}$ (or $\mathrm{SiN}$ ) probes are commercially used. In order to achieve higher spatial resolution, the sharper or finer probes are indispensable. Thus, from just after the discovery of CNTs (Iijima, 1991), 1-D nanocarbons such as CNTs and CNFs, have been thought as an ideal probe for SPMs, because of their high aspect ratio, nanoscale tip radius of curvature and chemical stability. Typical approaches to fabricate CNT- or CNF-tipped probes include the attachment or the direct growth of 1-D nanocarbons onto probe tips (Dai et al., 1996; Wong et al., 1997; Wong et al., 1998a; Wong et al., 1998b; Nagy et al., 1998; Nishijima et al., 1999; Nakayama et al., 2000). In the attachment methods, although high quality CNTs can be utilized, the attachment is done one-by-one manually or electrophoretically. So, this method is not suitable for the mass production to be used in industrial researches, but usable in laboratory research. On the other hand, the direct growth of a CNT onto an SPM tip by CVD was first demonstrated by Dai, et al (Dai et al., 1996). This CVD method has been expected to have a potential for mass production of CNT probes (Hafner et al., 1999a; Hafner et al., 1999b; Cheung et al., 2000). In fact, E.Yenilmez, et al. demonstrated the waferscale growth of single CNTs onto commercial-type Si cantilever tips by a so-called "surface growth CVD" (Yenilmez et al., 2002). In this method, however, an additional one-by-one post-processing of individual CNTs to tune their length is required for the practical use (Bhushan, 2003). Thus, in spite of the devoted much effort, the large-scale fabrication of practical CNT- or CNF-probes is still quite challenging.

As described above, in the ion irradiation method, ion-induced CNFs grow only on the sharp tips and SPM probes possess the sharp tips originally. In addition, they grow on the whole ion irradiated area. So, a batch fabrication of CNF-tipped probes (CNF probe) should be achievable using a large-scale ion gun.

Figure 11 shows a typical optical microscope image of an array of commercial Si cantilevers (tetragonal-type Si tips; Olympus) and SEM images of a CNF grown thereon using the ionirradiation method (Tanaka et al., 2007). The growth duration (ion-irradiation time) was 9 min. As seen in Figs. 11(c) and 11(d), a linear-shaped single CNF, about $800 \mathrm{~nm}$ in length, pointing in the ion-beam direction, grew only on the tip. The CNF was almost uniform in diameter, $\sim 30 \mathrm{~nm}$, along the growth direction. The length of CNF probes was well controllable by the growth time, because the CNFs increased in length with growth time. After the $32 \mathrm{~min}$ irradiation, for instance, CNFs were longer than $1.7 \mu \mathrm{m}$ in length. Independent of the growth time, CNF probes were linear in shape and almost uniform in diameter along the growth direction. Fine CNFs tended to grow for short irradiation duration $(<10 \mathrm{~min})$. Under the optimized growth condition, CNFs were batch-grown uniformly in length with the standard deviation of less than $10 \%$ ( 9 chips/batch in this experiment). Needless to say, the batch fabrication system can be readily scaled up by using a larger ion beam source. In fact, wafer-scale fabrication, more than 280 SPM chips in a 4inch wafer, was challenged, and $\sim 80 \%$ of the CNF probes batch-grown were suitable for practical uses as qualified probes. (Kitazawa et al., 2009) 

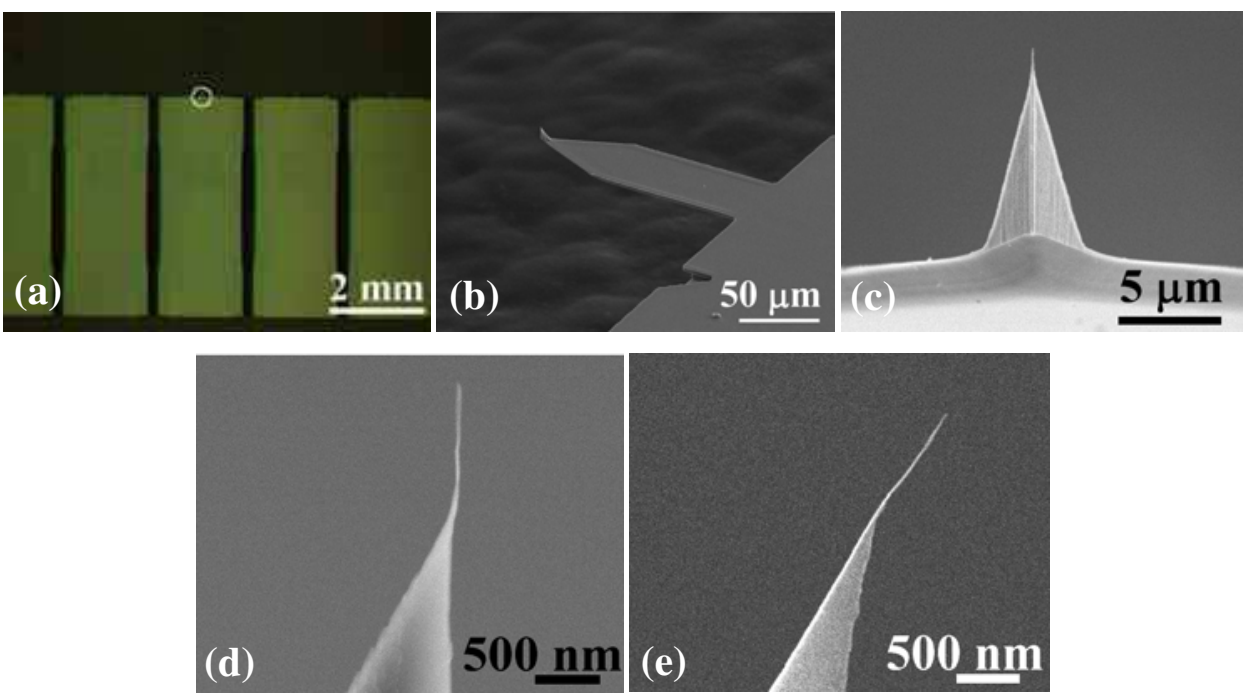

Fig. 11. (a) Optical microscope image of an array of SPM chips used for the batch growth (9 chips/batch). (b) SEM image of the cantilever of encircled area in (a). (c) and (d) Front-view and enlarged side-view SEM images of a typical CNF probe thus batch-grown, respectively. (e) SEM image of a CNF grown in 45o-derection to the cantilever plane. (Tanaka et al., 2007)

One of the most important applications for CNT or CNF probes is the precise analysis of deep trenches. For this application, probes should approach the bottom surface of the trench as perpendicularly as possible, in order to avoid the contact to the side wall of the trench with the probe. Thus, the controllability in the growth direction of CNFs is quite important. Since the ion-induced CNFs grow toward the ion beam direction (Tanemura et al., 2004b; Tanemura et al., 2005a; Tanemura et al., 2005b; Tanemura et al., 2006b), the growth direction of CNFs is readily controllable by incidence angle of ions, as typically exemplified in Fig. 11(e).

Figure 12(a) shows an SEM image of the villus-like structure to check the performace of the batch fabricated CNF probes, disclosing that the plastic nanocolumns of $50-60 \mathrm{~nm}$ in diameter and 40 - $50 \mathrm{~nm}$ in inter-nanocolumn spacing were densely arrayed (Kitazawa et al., 2009). A CNF probe used in this measurement was $16 \mathrm{~nm}$ in diameter, $353 \mathrm{~nm}$ in length, and $7.4 \mathrm{deg}$ in growth angle. The probe mounted angle was $12 \mathrm{deg}$, so that the actual angle of the probe tip was $4.6 \mathrm{deg}$. For a comparison, AFM observation using a conventional Si probe was also carried out. AFM images obtained using the CNF and the Si probes are shown in Figs. 12(b) and 12(c), respectively, with respective cross-sectional line profiles. The image obtained by the Si probe was distorted as seen in elliptical shapes of respective nanocolumns. By contrast, the AFM image attained by the CNF probe was not distorted, and as also seen in the cross-sectional line profile, side wall structure of nanocolumns was observed more symmetric and abrupt compared with that depicted using the Si probe. The superiority of the CNF probe was confirmed quantitatively by measuring the side-wall angles of 10 nanocolumns randomly selected. For the CNF probe, averaged wall angles of right- and left-sides of the nanocolumns measured $85.5^{\circ}\left(2.4^{\circ}\right.$ in standard deviation $\left.\sigma\right)$ and $80.6^{\circ}\left(1.8^{\circ}\right.$ in $\left.\sigma\right)$, respectively, whereas they were $86.0^{\circ}\left(1.5^{\circ}\right.$ in $\left.\sigma\right)$ and $73.8^{\circ}\left(6.0^{\circ}\right.$ in $\left.\sigma\right)$, respectively, for the $\mathrm{Si}$ probe. As is clear from this result, the CNF probe provided a symmetric profile with a less $\sigma$ value in the distribution of side-wall angles of nanocolumns. 


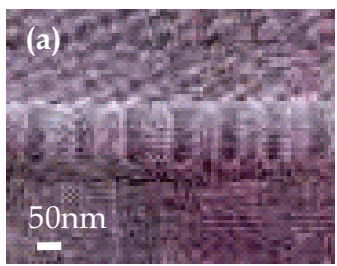

(b) CNF Probe
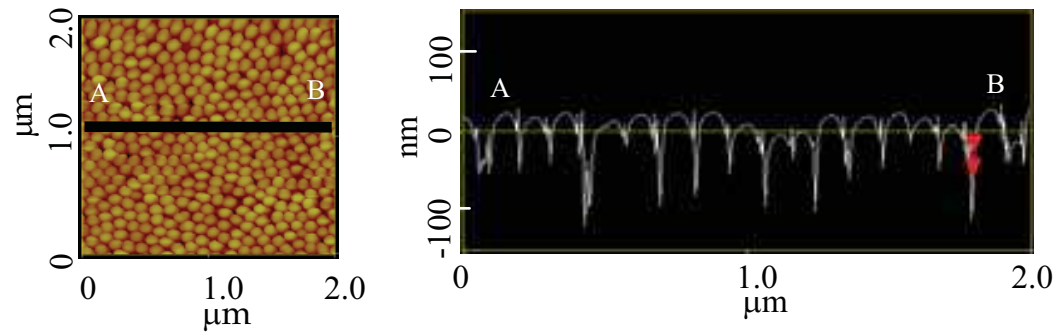

(c) Silicon Probe
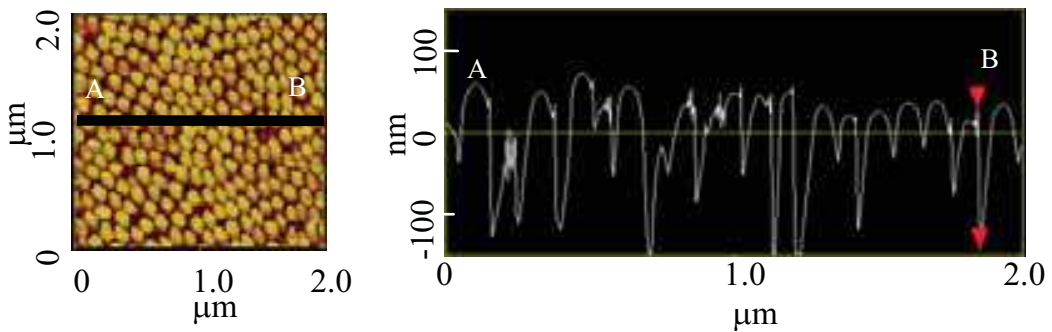

Fig. 12. (a) SEM image of a densely distributed plastic nanocolumn array and its AFM images obtained by (b) a CNF and (c) a conventional Si probes. (Kitazawa et al., 2009)

From a viewpoint of the practical use, easy handling of probes is also important. In case of CNT probes, for instance, a special care is required for AFM measurements. By contrast, $\mathrm{CNF}$ probes can be used as easily as conventional $\mathrm{Si}$ probes. This point is quite fascinating for the daily use. Thus, it is believed that the batch-fabricated CNF probes would be quite promising for various application fields.

\subsection{Application of carbon nanocomposite fibres to magnetic force microscope (MFM) probes}

As seen above, various kinds of metals, such as ferromagnetic metals, can be incorporated into ion-induced CNFs by a simultaneous supply of metals during $\mathrm{Ar}^{+}$-ion irradiation (Tanemura et al., 2005a; Tanaka et al., 2007; Wang et al., 2009; Wang et al., 2010a-c). If the metal incorporation is possible also for CNF probes, their magnetic, electrical, mechanical and chemical properties will be readily controllable, and thus their wider range of applications being realized.

Figure 13(a) shows an SEM image of a typical Co-CNF probe batch-fabricated (8 chips/batch) by Ar+-ion irradiation with a simultaneous Co supply (Sugita et al., 2009). For 
basal cantilevers, commercial Si probes (tetragonal-type Si tips; Olympus) were used. As clearly seen in the SEM image, a single nanofibre grew in the ion-beam direction on the original Si tip. As confirmed by the energy dispersive spectroscopy (EDS) analysis of a tip region of a nanofibre, $\mathrm{Co}$ and $\mathrm{C}$ were contained in the fibre, and hence proving that the nanofibre was a Co-CNF. Thus, similar to the pristine CNF probes, Co-CNFs probes are producible in a batch process readily.
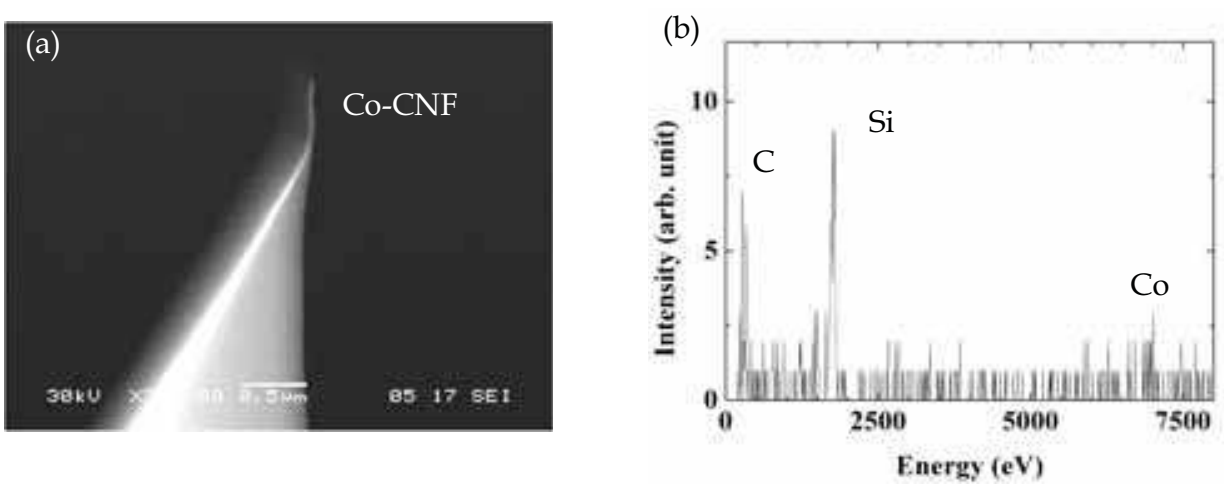

Fig. 13. (a) SEM image of a typical Co-CNF probe. (b) Typical EDS spectrum attained for a Co-CNF probe. (Sugita et al., 2009)

The Co-CNF probe shown in Fig. 13(a) was $20 \mathrm{~nm}$ in diameter and $400 \mathrm{~nm}$ in length. It was shorter in length than pristine CNFs fabricated under the identical ion-beam conditions without a Co supply, though their diameter was almost identical with that of pristine CNFs (Tanaka et al., 2007; Kitazawa et al., 2007; Kitazawa et al., 2008). As seen in the previous section, metal supplied CNFs formed on graphite substrates in general decrease in length with increasing the metal supply rate. This is also the case for Co-CNF probes. Co-CNF probes decreased in length almost linearly with an increase in Co supply rate, whereas their diameter was almost independent of the Co supply rate in the range of Co supply rate at which Co-CNFs are successfully formed. It should be emphasized that without thickening diameter remarkably an incorporation of metals into CNFs was readily achievable by the ion-irradiation with a simultaneous metal supply. This point is quite important for the development of the high performance MFM probes. Another possible method to produce nanocarbon based MFM probes is a post-deposition of a metal film onto 1-D nanocarbon probes. This method, however, increases the diameter of the 1-D nanocarbon, resulting in a decrease in the image resolution.

Figure 14 represents images taken in AFM and MFM modes using a Co-CNF probe batch fabricated for a magnetically recorded media (used hard disk) (Sugita et al., 2009). Small surface roughness of the film was observable in the AFM image [Fig. 14(a)], implying that the Co-CNF probe possessed an enough spatial resolution in AFM mode. In the MFM image, clear bright and dark stripes corresponding to magnetic signal patterns were observed. So, the ion-induced Co-CNF probe is applicable also as an MFM probe.

For the better image resolution finer probes are required, and for higher MFM sensitivity larger amount of Co should be included in the Co-CNF probe. As was described in the previous section, however, an excess supply of the metal to CNFs tend to suppress the CNF formation and formed metal supplied CNFs tend to be larger in diameter. So, for the best 

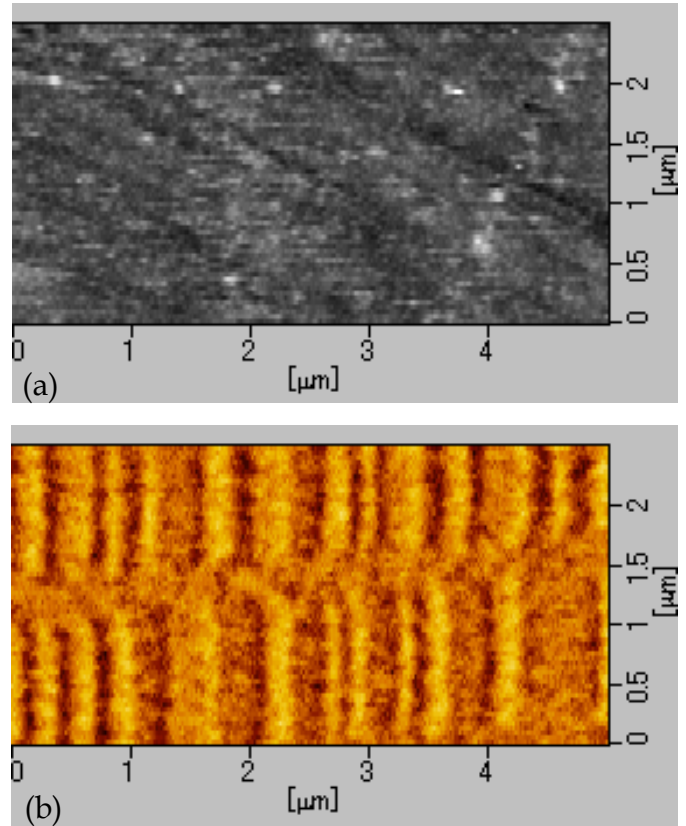

Fig. 14. (a) AFM and (b) MFM images observed by a batch-grown Co-CNF probe. (Sugita et al., 2009)

MFM performance, Co content and Co-CNF diameter should be optimized. This is our next subject. In addition, in this ion irradiation method, metal alloys whose ferromagnetic property are stronger than Co can be supplied. MFM performance of such a alloy supplied CNF probes is quite interesting. These experiments are in progress.

\section{Conclusions and future prospects}

The room-temperature fabrication of carbon-based nanocomposite fibres by the ionirradiation method and their applications to AFM and MFM probes were demonstrated. CNF-based AFM probes have already been released for the commercial uses. For a broader range of industrial researches, their stable production in larger wafer-scale is indispensable. In addition, the importance in the controllability in electrical, mechanical, magnetic and chemical properties of the nanoprobes will be increasing in practical applications, especially in nanotechnology and biotechnology fields. The MFM probe demonstrated here is the first step of these "functionalized probes" based on the composite CNFs. For the development of such advanced nanocarbon based probes, basic researches on the dependence of those properties on the amount of the contained metals in CNFs are necessary. In addition, the control in the crystalline structure of composite CNFs by electron current flow is quite important from viewpoints of both fundamental research and application. The investigations along these lines are now being undertaken.

Besides the probe applications, ion-induced pristine and composite CNFs are applicable to field electron emission devices (Tanemura et al., 2005b; Tanemura et al., 2005c; Tan et al., 2006; Sim et al., 2007; Ghosh et al., 2010; Wang et al., 2009). In addition, by using the ion 
irradiation method, $\mathrm{ZnO}$ based composite nanoneedles for ultra violet laser emission (Lau et al., 2005; Tanemura et al., 2006c; Yang et al., 2006; Tanemura et al., 2007) and spintronics devices (Herng et al., 2007; Herng et al., 2009) can be fabricated. Furthermore, various kinds of metal- and semiconductor- nanocomposites can be fabricated at low temperature by the ion-irradiation method (Ghosh et al., 2010b; Kutusna et al., 2009; Miyawaki et al, 2008). Thus, the ion-irradiation method is believed to be a new route to fabricate nanocomposite materials at low temperatures.

\section{References}

Alexandrou, I.; Ang, D. K. H.; Mathur, N. D.; Haq, S.\& Amaratunga, G. A. J. (2004). Encapsulated Nanowires Formed by Nanotube-Assisted Oriented Attachment. Nano Lett., 4, 11, 2299-2302, ISSN 1530-6984.

Asaka, K.; Nakahara, H.; \& Saito, Y. (2008). Nanowelding of a multiwalled carbon nanotubeto metal surface and its electron field emission properties. Appl. Phys. Lett., 92, 2, 023114-1-023114-3, ISSN 0003-6951.

Auciello, O. \& Kelly, R. (1984). Ion Bombardment Modification of Surfaces (Elsevier, ISBN 9780444423658, Tokyo).

Bao, J.; Zhou, Q.; Hong, J.\& Xu, Z. (2002). Synthesis and magnetic behavior of an array of nickel-filled carbon nanotubes. Appl. Phys. Lett., 81, 24, 4592-4594, ISSN 0003-6951.

Bhushan, B. (ed), (2003). Springer Handbook of Nanotechnology (Springer-Verlag, ISBN 9783540012184, Berlin).

Binnig, G.; Rohrer, H.; Gerber, Ch. \& Weibel, E. (1982). Surface studies by scanning tunneling Microscopy. Phys. Rev. Lett. 49, 1, 57-61, ISSN 0031-9007.

Boskovic, B. O.; Stolojan, V.; Khan, R. U. A.; Haq, S. \& Silva, S. R. P. (2002). Large-area synthesis of carbon nanofibres at room temperature. Nature Materials, 1, 3, 165-168, ISSN 1476-1122.

Cheung, C. L.; Hafner, J. H.; Odom, T. W.; Kim, K.\& Lieber, C. M. (2000). Growth and fabrication with single-walled carbon nanotube probe microscopy tips. Appl. Phys. Lett. 76, 21, 3136-3138, ISSN 0003-6951.

Czanderna, A. W.; Madey, T. E. \& Powell, C. J. (eds) (1998). Beam Effects, Surface Topography, and Depth Profiling in Surface Analysis (Plenum Press, ISBN 978-0306458965, New York and London).

Dai, H.; Hafner, J. H.; Rinzler, A. G..; Colbert, D. T.\& Smally, R. E. (1996). Nanotubes as nanoprobes in scanning probe microscopy. Nature, 384, 147-150, ISSN 0028-0836.

Elías, A. L.; Rodríguez-Manzo, J. A.; McCartney, M. R.; Golberg, D.; Zamudio, A.; Baltazar, S. E.; López-Urías, F.; Muñoz-Sandoval, E.; Gu, L.; Tang, C. C.; Smith, D. J.; Bando, Y.; Terrones, H.\& Terrones, M. (2005). Production and Characterization of SingleCrystal FeCo Nanowires Inside Carbon Nanotubes. Nano Lett., 5, 3, 467-472, ISSN 1530-6984.

Floro, J. A.; Rossnagel, S. M. \& Robinson, R. S. (1983). Ion-bombardment-induced whisker formation on graphite. I Vac. Sci. Technol. A, 1, 3, 1398-1402. ISSN 0734-2101.

Ghosh, P.; Yusop, M. Z.; Satoh, S.; Subramanian, M.; Hayashi, A.; Hayashi, Y. \& Tanemura, M. (2010). Transparent and Flexible Field Electron Emitters Based on the Conical Nanocarbon Structures. el Am. Chem. Soc., 132, 12, 4034-4035, ISSN 0002-7863. 
Ghosh, P.; Kutsuna, M.; Kudo, M.; Hayashi, A.; Hayashi, Y. \& Tanemura, M. (2010) Fabrication and Morphological Control of Ion-induced Zinc Nanostructures. eburnal of Nanoscience and Nanotechnology 10, 10, 6677-6682, ISSN 1550-7033.

Hafner, J. H.; Cheung, C. L. \& Lieber, C. M. (1999). Growth of nanotubes for probe microscopy tips. Nature, 398, 761-762, ISSN 0028-0836.

Hafner, J. H.; Cheung, C. L. \& Lieber, C. M. (1999). Direct Growth of Single-Walled Carbon Nanotube Scanning Probe Microscopy Tips. I Am. Chem. Soc., 121, 41, 9750-9751, ISSN 0002-7863.

Herng, T. S.; Lau, S. P.; Yu, S. F.; Yang, H. Y.; Wang, L.; Tanemura, M. \& Chen, J. S. (2007). Magnetic anisotropy in the ferromagnetic $\mathrm{Cu}$-doped $\mathrm{ZnO}$ nanoneedles. Appl. Phys. Lett., 90, 3, 032509-1-3, ISSN 0003-6951.

Herng, T. S.; Lau, S. P.; Wei, C. S.; Wang, L.; Zhao, B. C.; Tanemura, M. \& Akaike, Y. (2009). Stable ferromagnetism in p-type carbon-doped $\mathrm{ZnO}$ nanoneedles. Applied Physics Letters, 95, 13, 133103-1-3, ISSN 0003-6951.

Hofmann, S.; Ducati, C.; Robertson, J. \& Kleinsorge,B. (2003). Low-temperature growth of carbon nanotubes by plasma-enhanced chemical vapor deposition. Appl. Phys. Lett., 83, 1, 135-137, ISSN 0003-6951.

Iijima, S. (1991). Helical microtubules of graphitic carbon. Nature, 354, 56-59, ISSN 00280836.

Kitazawa,M.; Ohta, R.; Tanaka, J. \& Tanemura, M. (2007). Electrical Properties of Single Carbon Nanofibers Grown on Tips of Scanning Probe Microscope Cantilevers by Ion Irradiation. don. el Appl. Phys., 46, 8B, 5607-5610, ISSN 0021-4922.

Kitazawa, M.; Ohta, R.; Sugita, Y.; Tanaka, J. \& Tanemura, M. (2008). Characterization of small-scale batch-fabricated carbon nanofiber probes . I Phys. Conf. Ser., 100, 5, 052005-1-5, ISSN 1742-6588.

Kitazawa, M.; Ohta, R.; Sugita, Y.; Inaba K. \& Tanemura, M. (2009). Wafer-scale production of carbon nanofiber probes. I Vacuum Science and Technology B, 27, 2, 975-979, ISSN 1071-1023.

Kutsuna, M.; Ghosh, P.; Kudo, M.; Tanemura, M. \& Hayashi, Y. (2009) Fabrication of well ordered $\mathrm{Zn}$ nanorod arrays by ion irradiation method at room temperature and effect on crystal orientations. Applied Surface Science, 256, 5, 1481-1485, ISSN 01694332.

Lau, S. P.; Yang, H. Y.; Yu, S. F.; Li, H. D.; Tanemura, M.; Okita, T.; Hatano, H. \& Hng, H. H. (2005). Laser action in $\mathrm{ZnO}$ nanoneedles selectively grown on silicon and plastic substrates. Appl. Phys. Lett., 87, 1, 013104-1-3. ISSN 0003-6951.

Leonhardt, A.; Ritschel, M.; Kozhuharova, R.; Graff, A.; Mühl, T.; Huhle, R.; Mönch, I.; Elefant, D.\& Schneider, C. M. (2003). Synthesis and properties of filled carbon nanotubes. Diamond Relat. Mater, 12, 3-7, 790-793, ISSN 0925-9635.

Miyawaki, A.; Sugita, Y.; Yamaguchi, K.; Hayashi, T.; Hayashi, Y.; Tokunaga. T. \& Tanemura, M. (2008): Low-temperature fabrication of Ge nanostructures by ion irradiation. Transactions of the Materials Research Society of ctopan, 33, 4, 1015-1018.

Nagy, G..; Levy, M.; Scarmozzino, R.; Osgood, R. M.; Dai, Jr., H.; Smalley, R. E.; Michaels, C. A.; Flynn, G. W.; McLane, G. F. (1998). Carbon nanotube tipped atomic force microscopy for measurement of $<100 \mathrm{~nm}$ etch morphology on semiconductors. Appl. Phys. Lett., 73, 4, 529-531, ISSN 0003-6951. 
Nakayama, Y.; Nishijima, H.; Akita, S.; Hohmura, K. I.; Yoshimura, S. H.\& Takeyasu, K. (2000). Microprocess for fabricating carbon-nanotube probes of a scanning probe microscope. IV Vac. Sci. Technol. B, 18, 2, 661-664, ISSN 1071-1023.

Nishijima, H.; Kamo, S.; Akita, S.; Nakayama, Y.; Hohmura, K. I.; Yoshimura, S. H. \& Takeyasu, K. (1999). Carbon-nanotube tips for scanning probe microscopy: Preparation by a controlled process and observation of deoxyribonucleic acid. Appl. Phys. Lett., 74, 26, 4061-4063, ISSN 0003-6951.

Pan, Z. W.; Xie, S. S.; Chang, B. H.; Wang, C. Y.; Lu, L.; Liu, W.; Zhou, W. Y. \& Li, W. Z. (1998). Very long carbon nanotubes. Nature, 394, 631-632, ISSN 0028-0836.

Ren, Z. F.; Huang, Z. P.; Xu, J. W.; Wang, J. H.; Bush, P.; Siegal, M. P. \& Provencio, P. N. (1998). Synthesis of Large Arrays of Well-Aligned Carbon Nanotubes on Glass. Science, 282, 5391, 1105-1107, ISSN 0036-8075.

Schneider, C. M.; Zhao, B.; Kozhuharova, R.; Groudeva-Zotova, S.; Mühl, T.; Ritschel, M.; Mönch, I.; Vinzelberg, H.; Elefant, D.; Graff, A.; Leonhardt, A.\& Fin, J. (2004). Towards molecular spintronics: magnetotransport and magnetism in carbon nanotube-based systems. Diamond Relat. Mater, 13, 2, 215-220, ISSN 0925-9635.

Sim, H. S.; Lau, S. P.; Yang, H. Y. ;Ang, L. K.; Tanemura, M. \& Yamaguchi, K. (2007). Reliable and flexible carbon-nanofiber-based all-plastic field emission devices. Appl. Phys. Lett., 90, 14, 143103-1-3, ISSN 0003-6951.

Sugita, Y.; Kitazawa, M.; Yusop, M. Z. M.; Tanemura, M.; Hayashi Y. \& Ohta, R. (2009). Application of ion-induced carbon nanocomposite fibers to magnetic force microscope probes. I Vacuum Science and Technology B, 27, 2, 980-983, ISSN 10711023.

Takeuchi, D.; Wang, Z. P.; Yamaguchi, K.; Kitazawa, M.; Hayashi, Y. \& Tanemura, M. (2008). Morphological and structural characterization of metal-doped carbon nanofibers synthesized at room temperature', el Phys. Conf. Ser. 100, 1, 012029-1-4, ISSN 17426588.

Takeuchi, D.; Wang, Z. P.; Miyawaki, A.; Yamaguchi, K.; Suzuki, Y. ;Tanemura, M.; Hayashi Y. \& Somani, P. R. (2008). Room-temperature synthesis and characterization of cobalt-doped carbon nanofibers. Diamond and Related Materials, 17, 4-5, 581-584, ISSN 0925-9635.

Tan, T. T.; Sim, H. S.; Lau, S. P.; Yang, H. Y.; Tanemura, M. \& Tanaka, J. (2006). X-ray generation using carbon nanofibre based flexible field emitters. Appl. Phys. Lett., 88, 10, 103105-1-3, ISSN 0003-6951.

Tanaka, J.; Kitazawa, M.; Tanemura, M. \& Ohta, R. (2007). Small-scale batch fabrication of carbon nanofiber probes. I Phys. Conf. Ser., 61, 1, 1167-1174, ISSN 1742-6588.

Tanemura, M.; Iwata, K.; Takahashi, K.; Fujimoto, Y.; Okuyama, F.; Sugie, H. \& Filip, V. (2001). Growth of aligned carbon nanotubes by plasma-enhanced chemical vapor deposition: Optimization of growth parameters. II Appl. Phys., 90, 3, 1529-1533, ISSN 0021-8979.

Tanemura, M.; Yamauchi, H. ; Yamane, Y. ; Okita, T. \& Tanemura, S. (2004). Controlled fabrication of Mo-seeded Si microcones by $\mathrm{Ar}^{+}-$ion bombardment. Nucl. Instr. and Meth., B, 215, 137-142.

Tanemura, M.; Okita, T.; Yamauchi, H.; Tanemura, S. \& Morishima, R. (2004). Roomtemperature growth of a carbon nanofiber on the tip of conical carbon protrusions. Appl. Phys. Lett., 84, 19, 3831-3833, ISSN 0003-6951. 
Tanemura, M.; Okita, T.; Tanaka, J.; Yamauchi, H.; Miao, L.; Tanemura, S. \& Morishima, R. (2005). Room-temperature growth of carbon nanofibers induced by $\mathrm{Ar}^{+}$-ion bombardment. Eur. Phys. D, 34, 1-3, 283-286, ISSN 1434-6060.

Tanemura, M.; Tanaka, J.; Itoh, K.; Fujimoto, Y.; Agawa, Y.; Miao, L. \& Tanemura, S. (2005). Field electron emission from sputter-induced carbon nanofibers grown at room temperature. Appl. Phys. Lett., 86, 11, 113107-1-3, ISSN 0003-6951.

Tanemura, M.; Tanaka, J.; Itoh, K.; Okita, T.; Miao, L. ;Tanemura, S.; Lau, S. P.; Huang, L.; Agawa, Y. \& Kitazawa, M. (2005). Self-Regenerative Field Emission Source. Appl. Phys. Lett., 87, 19, 193102-1-3. ISSN 0003-6951.

Tanemura, M.; Hatano, H.; Kitazawa, M.; Tanaka, J.; Okita, T.; Lau, S. P.; Yang, H. Y.; Yu, S. F.; Huang, L.; Miao, L. \& Tanemura, S. (2006). Room-temperature growth of carbon nanofibers on plastic substrates. Surface Science, 600, 18, 3663-3667, ISSN 0039-6028.

Tanemura, M.; Kitazawa, M.; Tanaka, J.; Okita, T.; Ohta, R.; Miao, L. \& Tanemura, S. (2006). Direct growth of a single carbon nanofiber onto a tip of scanning probe microscopy induced by ion irradiation. epn. cl Appl. Phys., 45, 3B, 2004-2008, ISSN 0021-4922.

Tanemura, M.; Okita, T.; Tanaka, J.; Kitazawa, M.; Itoh, K.; Miao, L.; Tanemura, S.; Lau, S. P.; Yang, H. \& Huang, L. (2006). Room-temperature growth and applications of carbon nanofibers: A review. IEEE Transactions on Nanotechnology, 5, 5, 587- 594, ISSN 1536-125X.

Tanemura, M.; Hatano, H.; Kudo, M.; Ide, N.; Fujimoto, Y.; Miao, L.; Yang, H. Y.; Lau, S. P.; Yu S. F. \& Kato, J. (2007). Low-temperature fabrication and random laser action of doped zinc oxide nanoneedles. Surface Science ,601, 18, 4459-4464, ISSN 0039-6028.

Thess, A.; Nikolaev, P.; Dai, H. J.; Petit, P.; Robert, J.; Xu, C. H.; Lee, Y. H.; Kim, S. G..; Rinzler, A. G..; Cocert, D. T.; Scuseria, G.. E.; Tomanek, D. T.; Fisher, J. E. \& Smalley, R. E. (1996). Crystalline Ropes of Metallic Carbon Nanotubes. Science, 273, 5274, 483-487, ISSN 0036-8075.

Tyagi, P. K.; Misra, A.; Singh, M. K.; Misra, D. S.; Ghatak, J.; Satyam, P. V. \& Normand, F. Le. (2005). High-resolution transmission electron microscopy mapping of nickel and cobalt single-crystalline nanorods inside multiwalled carbon nanotubes and chirality calculations. Appl. Phys. Lett., 86, 25, 253110-1-3, ISSN 0003-6951.

Vechten, J. A. V.; Solberg, W.; Batson, P. E.; Cuomo, J. J. \& Rossnagel, S. M. (1987). Kink site saturation mechanism for whisker growth under sputtering conditions . el Crystal Growth, 82, 3,289-294, ISSN 0022-0248.

Wang, Z.; Yamaguchi, K.; Takeuchi, D.; Hayashi, Y. \& Tanemura, M. (2009). Roomtemperature synthesis and characterisation of ion-induced iron-carbon nanocomposite fibers. Int. eI Nanotechnol., 6, 7/8, 753-761, ISSN 1475-7435.

Wang, Z.; Yusop, M. Z. M.; Hihara, T.; Hayashi, Y. \& Tanemura, M. (2010). Crystallinitycontrolled iron-carbon composite nanofibers-Synthesis and characteristic properties. el Crystal Growth, 312, 12-13, 1935-1939, ISSN 0022-0248.

Wang, Z.; Yusop, M. Z. M.; Hihara, T.; Hayashi, A.; Hayashi Y. \& Tanemura, M. (2010). Formation and growth mechanisms of ion-induced iron-carbon nanocomposites at room temperature. Applied Surface Science, 256, 21, 6371-6374, ISSN 0169-4332.

Wang, Z.; Yusop, M. Z. M.; Hihara, T.; Ghosh, P.; Hayashi, A.; Hayashi, Y. \& Tanemura, M. (2010). Fabrication of Ion-Induced Carbon-Cobalt Nanocomposite Fibers: Effect of Cobalt Supply Rate. eburnal of Nanoscience and Nanotechnology, in press, ISSN 15507033. 
Wehner, G. K. (1985). Cone formation as a result of whisker growth on ion bombarded metal surfaces. IV Vac. Sci. Technol.A, 3, 4, 1821-1835, ISSN 0734-2101.

Wong, E. W.; Sheehan, P. E. \& Lieber, C. M. (1997). Nanobeam Mechanics: Elasticity, Strength, and Toughness of Nanorods and Nanotubes. Science, 277, 5334, 1971-1975 ISSN 0036-8075.

Wong, S. S.; Harper, J. D.; Lansbury, P. T.\& Lieber, C. M. (1998). Carbon Nanotube Tips: High-Resolution Probes for Imaging Biological Systems. I Am. Chem. Soc., 120, 3, 603-604, ISSN 0002-7863.

Wong, S. S.; Woolley, A. T.; Odom, T. W.; Huang, J.; Kim, P.; Vezenov, D. V.\& Lieber, C. M. (1998). Single-walled carbon nanotube probes for high-resolution nanostructure imaging. Appl. Phys. Lett., 73, 23, 3465-3467, ISSN 0003-6951.

Yamaguchi, K.; Kitazawa, M.; Wang, Z. P.; Sugita, Y.; Tanaka, J.; Tanemura, M. \& Hayashi, Y. (2008). Room-temperature growth of ion-induced carbon nanofibers: Effects of ion species. Diamond and Related Materials, 17, 4-5, 525-528, ISSN 0925-9635.

Yang, H. Y.; Lau, S. P.; Yu, S. F.; Tanemura, M.; Okita, T.; Hatano, H.; Teng K. S. \& Wilks, S. P. (2006). Wavelength-tunable and high-temperature lasing in $\mathrm{ZnMgO}$ nanoneedles. Appl. Phys. Lett., 89, 8, 081107-1-3, ISSN 0003-6951.

Yenilmez, E.; Wang, Q.; Chen, R. J.; Wang, D.; Dai, H. (2002). Wafer scale production of carbon nanotube scanning probe tips for atomic force microscopy. Appl. Phys. Lett., 80, 12, 2225-2227, ISSN 0003-6951.

Yusop, M. Z.; Yamaguchi, K.; Suzuki, T.; Ghosh, P.; Hayashi, A.; Hayashi, Y. \& Tanemura, M. (2010). Morphology and size of ion induced carbon nanofibers: Effect of ion incidence angle, sputtering rate and temperature. efpn. el Appl. Phys., in press, ISSN 0021-4922.

Zamri,M.; Ghosh, P.; Wang, Z. P.; Kawagishi, M.; Hayashi, A.; Hayashi, Y. \& Tanemura, M. (2010). Direct growth of carbon nanofibers on metal mesh substrates by ion irradiation method. eburnal of Vacuum Science \& Technology B, 28, 2, C2C9-C2C12, ISSN 1071-1023. 


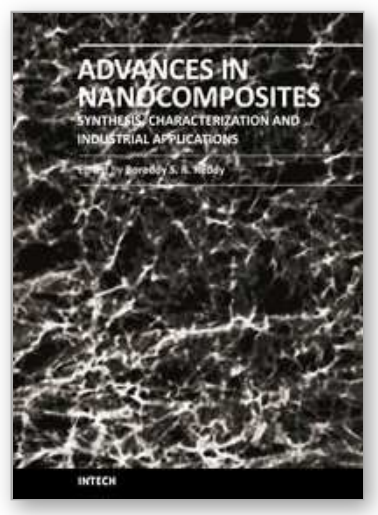

\author{
Advances in Nanocomposites - Synthesis, Characterization and \\ Industrial Applications
}

Edited by Dr. Boreddy Reddy

ISBN 978-953-307-165-7

Hard cover, 966 pages

Publisher InTech

Published online 19, April, 2011

Published in print edition April, 2011

Advances in Nanocomposites - Synthesis, Characterization and Industrial Applications was conceived as a comprehensive reference volume on various aspects of functional nanocomposites for engineering technologies. The term functional nanocomposites signifies a wide area of polymer/material science and engineering, involving the design, synthesis and study of nanocomposites of increasing structural sophistication and complexity useful for a wide range of chemical, physicochemical and biological/biomedical processes. "Emerging technologies" are also broadly understood to include new technological developments, beginning at the forefront of conventional industrial practices and extending into anticipated and speculative industries of the future. The scope of the present book on nanocomposites and applications extends far beyond emerging technologies. This book presents 40 chapters organized in four parts systematically providing a wealth of new ideas in design, synthesis and study of sophisticated nanocomposite structures.

\title{
How to reference
}

In order to correctly reference this scholarly work, feel free to copy and paste the following:

Masaki Tanemura and Masashi Kitazawa (2011). Fabrication of lon-Induced Carbon Nanocomposite Fibres and their Application to Magnetic Force Microscope Probes, Advances in Nanocomposites - Synthesis, Characterization and Industrial Applications, Dr. Boreddy Reddy (Ed.), ISBN: 978-953-307-165-7, InTech, Available from: http://www.intechopen.com/books/advances-in-nanocomposites-synthesis-characterizationand-industrial-applications/fabrication-of-ion-induced-carbon-nanocomposite-fibres-and-their-application-tomagnetic-force-micro

\section{INTECH}

open science | open minds

\section{InTech Europe}

University Campus STeP Ri

Slavka Krautzeka 83/A

51000 Rijeka, Croatia

Phone: +385 (51) 770447

Fax: +385 (51) 686166

www.intechopen.com

\section{InTech China}

Unit 405, Office Block, Hotel Equatorial Shanghai

No.65, Yan An Road (West), Shanghai, 200040, China 中国上海市延安西路65号上海国际贵都大饭店办公楼 405 单元

Phone: +86-21-62489820

Fax: $+86-21-62489821$ 
(C) 2011 The Author(s). Licensee IntechOpen. This chapter is distributed under the terms of the Creative Commons Attribution-NonCommercialShareAlike-3.0 License, which permits use, distribution and reproduction for non-commercial purposes, provided the original is properly cited and derivative works building on this content are distributed under the same license. 